\title{
ABRAPALABRA: \\ DEL MUNDO COMO ESCRITURA
}

POR

FRANCISCO JAVIER LASARTE VALCARCEL

Circulan desde fechas recientes las ediciones venezolana y cubana de Abrapalabra ${ }^{1}$, Premio Casa de las Américas de 1979. Es la segunda novela de Luis Britto García, quien además ha publicado dos colecciones de relatos - Los fugitivos (1964) y Rajatabla (1970), también Premio Casa de las Américas--, una primera novela -Vela de armas (1970) - y algunas piezas teatrales.

La edición de Abrapalabra ha sido largamente esperada, al menos en el ámbito literario nacional. Parte de la expectativa despertada puede recogerse a través de una serie de entrevistas realizadas a un grupo selecto de críticos venezolanos y publicadas en las páginas culturales de $E l$ Nacional $^{2}$. En ellas se intentó ofrecer el diagnóstico de lo que produjo la década de los setenta en materia de literatura venezolana. Por momentos, la fecundidad o insuficiencia de toda la producción narrativa parecía descansar sobre los juicios que este voluminoso texto pudiera suscitar.

Una vez puesta en circulación, la polémica en torno a la novela comenzó a tomar forma a través de notas periodísticas y de comentarios que rara vez trascendían los límites de lo conversacional. El carácter fundamentalmente doméstico de estos juicios impiden una confrontación seria de criterios, aunque sí valga la pena recoger como hecho elemental de recepción su presencia manifiesta. Su importancia sólo puede determinarse a partir de límites nacionales, de las peculiares alternativas planteadas en la vida cultural venezolana. Dichos juicios cuestionaban, grosso modo, la oscuridad, el exceso de letra impresa, la ausencia de acabamiento en algunas anécdotas $y$, en algunos casos, la ambición un tanto desmedida e inadecuada de la novela. Lo lamentable de estos juicios es que en su mayoría respondían a lecturas no comprensivas, carentes del mínimo rigor y animadas por vagas impresiones;

\footnotetext{
${ }^{1}$ Seguimos la edición venezolana de Abrapalabra (Caracas: Monte Avila Editores, 1980).

${ }^{2}$ Serie de entrevistas en cuatro entregas, realizadas por Nabor Zambrano, bajo el título de "La crítica y la literatura de los 70", en Páginas Culturales del Cuerpo C. El Nacional. (Caracas, 7-10 de febrero, 1980)
} 
cuandono, parecían arrastrar veladas rémorasy complejos, comoya es tradicional en cierta crítica periodística y académica con respecto a los más válidos intentos de nuestra literatura: campean rechazos, improductivos elogios o silencios. Es como si el ciclo clausurado por Gallegos hubiera significado una hecatombe; como si la nueva narrativa hispanoamericana fuese un coto reservado a ciertos nombres privilegiados o a ciertos países del continente, a pesar de los índices contrarios que establecen, en las últimas dos décadas, la recepción del Premio Biblioteca Breve, por Adriano González León, las numerosas ediciones extranjeras de la obra narrativa de Salvador Garmendia, la gran difusión de la última novela de Miguel Otero Silva y los éxitos internacionales del mismo Britto Garcia.

Estamos en presencia de una novela que, en su misma composición, propone la renovación formal del género. Intento que, por lo menos desde inicios de los años sesenta, conforma una de las más valiosas corrientes de la narrativa latinoamericana. Basta pensar en novelistas como Cortázar o Cabrera Infante. No se trata, sin embargo, de plantear problemas de originalidad. Estos nos conducirían a un regateo erudito del que ni Cervantes saldría bien librado. Lo grave resulta de la falta de vigencia por prematura caducidad o inadecuadas asimilaciones de fórmulas, por pobreza de planteamientos o incoherencias entre visiones y proposiciones estéticas. Este no es el caso de Abrapalabra.

Formalmente la novela supone la superposición de relatos de muy diverso asunto y, en apariencia, de una débil o nula conexión. Pero sólo en apariencia, pues existen elementos lingüísticos, estructurales y conceptuales definidores de una íntima y efectiva fusión en torno a núcleos de sentido que posibilitan la incorporación de los relatos a un sólido espacio novelesco. Entre otros, existen en el texto dos niveles de lectura superpuestos que resumen gran parte de la proposición novelesca. En una primera instancia, la novela se nos presenta como un intento de interpretación de una realidad histórica en su proceso y en su estado más actual. En una segunda instancia, podemos considerarla como un texto que reflexiona sobre sí mismo, una "máquina de novelar" que cuestiona su propio instrumento: la palabra, llegando a establecer una suerte de visión ontológica de la realidad representada en la novela y del mismo proceso de la escritura, entendido como posibilidad de conocimiento de una determinada realidad.

La novela está dividida en tres partes y su disposición es similar a la de un tríptico -l mismo Britto García ha señalado su semejanza con El Jardín de las Delicias ${ }^{3}$. A su vez, esta división contiene el desarrollo de diversos ciclos paralelos, que muestran, en parte, el intento totalizador del planteamiento novelesco. En este sentido cabe pensar en un ciclo que contempla la vida humana desde su infancia y adolescencia hasta su madurez y agotamiento, en un ciclo que abarca distintas fases históricas y que podría delimitarse en base

${ }^{3}$ Entrevista a Luis Britto García, en El Diario de Caracas (2 de mayo de 1980): 20-21. 
a las etapas de Conquista y Colonia, vida independiente y perspectivas o estados de la vida actual; y en otro ciclo que presenta la evolución del lenguaje desde su aprendizaje hasta su crisis e insuficiencia. En torno a estos núcleos se integran diversas temáticas, se construyen y cuestionan los símbolos prefiguradores de una totalidad específica y se sucede el proceso de escritura cifrado en la palabra que todo lo entrelaza y lo envuelve. A la manera de una novela-mandala, Abrapalabra puede considerarse como un compendio o suma, como un mural apocalíptico en el que se pretende asumir una totalidad de posibilidades, incluido el planteamiento autorreflexivo de su proceso de producción, a modo de guiño destinado al lector.

Los personajes protagonistas de los distintos relatos se definen en base a sus relaciones con el medio y a la solución de sus destinos personales. Forman una extensa galería cuyo recorrido conduce progresivamente a la clausura del mundo. La estructura significativa de este universo de relaciones se delimita sobre los elementos básicos del poder, la rebeldía y la instauración de un proceso definido por la degradación común. Sobre este último aspecto, los destinos parecen resolverse en términos de caídas y asqueamientos-Moncho-; anulación de personalides, culpas y obsesivos círculos _el asesino del Doctor Milagroso-; prodigiosas evasiones y estados autocontemplativos-Duque de Rocanegras-; abandonos últimos -Alba-, o nihilismos soñadores de universos aniquilantes - Micael-. Esta caracterización configura un mundo que propende a resaltar sus aspectos más negativos. Pero esta degradación se vincula estrechamente a las conexiones que establecen los personajes con distintas esferas de poder. El poder es caracterizado en la novela de diversa manera. Puede definirse en base a la escalada inescrupulosa del político, cada vez más dueño de los hilos ocultos de la vida social; en base a la destrucción total de una cultura, como sucede con los relatos que describen hechos o situaciones de la conquista y la colonización, o puede presentarse como la intuición de fuerzas inaccesibles, superiores, que pugnan por la anulación o la supervivencia final del cosmos. Abrapalabra plantea, en su desarrollo, la investigación de una suerte de macrouniverso en el que el poder representado en estos agentes, reconocibles o extraños, somete a los habitantes de la novela al congelamiento, a una prisión ilimitada. La agresión manifiesta o su ocultamiento por símbolos y palabras son sus instrumentos.

A modo de contrapeso o excepción, encontramos otros personajes u otras fuerzas signadas por su oposición a ultranza frente al estado de cosas. Es el caso de los elementos del mundo natural en los relatos referidos a la Conquista; de los esclavos poseedores del reino de la noche; de Alvaro Luque y, sobre todo, de la figura de Rubén: Rubén es el personaje que, a pesar del fracaso de la lucha armada contra un proceso político y del doloroso exilio, se caracteriza por su capacidad de recuperación, por su actitud permanente de lucha contra situaciones inicuas. Consideración especial también merece la figura del prestidigitador, que, de alguna forma, asume todos los personajes anteriores, todas las historias 
y soluciones. En su continua peripecia por el mundo es destruido para resurgir a la vida, porque en sus "trucos de espejos" asume también la palabra y el mensaje. Estos son personajes que, a pesar de muertes o de imposibilidades de acceso al conocimiento cabal, se mantienen como opciones abiertas al renacimiento.

Otro aspecto reseñable con respecto al mundo conformado por los personajes es la materia de la que provienen y que los caracteriza. Una gran cantidad de ellos son préstamos hechos a la historia, la literatura o a la llamada subliteratura. Es el caso, entre otros, de Windsor McKay, Houdini, el Duque de Rocanegras, Moncho, el Descubridor, el Viajero de Indias, el Doctor Milagroso o el pícaro Pablos. Sin embargo, de este nivel inmediato de la realidad se toman nombres y se desechan precisiones. Más aún, lo que se pretende con estos pequeños homenajes es el cuestionamiento de ciertas nociones, símbolos o mitos cul turales forjados en torno a determinados estados de la historia. Importa la inserción de la historia en tanto que define la cultura actual, pues su tratamiento se centra sobre mecanismos manipuladores y productores de arquetipos culturales.

Este rasgo de mediatez y abstracción ejercido sobre la realidad novelesca se suma a otra de las peculiaridades del mundo abrapalabresco: la progresiva desrealización a la que se ven sometidos personajes y situaciones. Los límites de lo usual se tornan evanescentes, ascendiendo o degenerando en laberintos mentales, fantasmagorías y espacios rítmicos. Dicha desrealización apunta hacia la segunda instancia -más englobante-de la lectura comprensiva de la novela: de la escritura en sí misma.

El título de la novela se nos ofrece como una clave. Al respecto, nos confiamos - justamente en este caso- a la explicación de Britto García: “Abrapalabra' es una fórmula mágica que resume a la vez los poderes, las potencialidades y las limitaciones de la palabra". Al tiempo que expone la relación del término con su equivalente inmediato $\mathrm{y}$ plantea su propia concepción de la escritura:

"Abracadabra" es una fórmula mágica del hebreo que significa: "arroja tu lanza hasta la muerte". La palabra no es otra cosa que la lanza del intelecto. La posición de las cosas es dada por esa especie de objeto abstracto que él arroja hacia ellas y con las cuales las mata, apoderándose de ellas y creando un universo mental 4 .

Esto explica la condición desrealizada del mundo novelesco con respecto al nivel de lo factible. No sólo se tiende a desdibujar fronteras de anécdotas y personajes, pues el planteamiento se traduce en una constante reflexión sobre el lenguaje desde el lenguaje mismo. El cuestionamiento de la escritura se cifra en las posibilidades de conocimiento u ocultamiento que la mente y el lenguaje humanos puedan ejercer en sus búsquedas comprensivas de realidadcs y

4 Entrevista inédita a Luis Britto García, realizada por J.L. en mayo de 1980. 
destinos; destinos y lenguajes, a su vez, condicionados por otras entidades manipuladoras; y así, hasta concretar la existencia del mundo como un laberinto, como un combate de tendencias contradictorias que tienden a anularse encerradas en una especie de círculo infernal.

Por otra parte, resulta interesante verificar cómo, en Abrapalabra, determinados recursos lingüísticos, la selección de ciertos elementos semánticos reiterativos y la utilización de procedimientos narrativos particulares reproducen, en sus respectivos niveles, el esquema significativo de la estructura novelesca.

Profusas adjetivaciones, encabalgamientos, abrumadoras repeticiones rupturas sintácticas, yuxtaposición de discursos, supresión de signos de puntuación, discursos sobresaturados de coordinaciones o subordinaciones, construcciones hiperbólicas, disposiciones tipográficas se repitan de unos a otros relatos a pesar de la diversidad de los asuntos, uniformando el sentido por el deslumbramiento del ritmo. La reiteración en distintos relatos de elementos tales como los ojos, la mano, las moscas, el estallido o la luz, cumple una función integradora similar. La novela en su interior se revela como una espesa red de intercambios significativos, en la que lo principal es la apertura hacia el sentido. Este proceso de fijación por/de la palabra a través del discurso del escritor implícito impone una ausencia de acabamiento de anécdotas, de desarrollo psicológico de personajes, en beneficio de la descripción de un estado expectante.

A nivel de la narración, el apresamiento de la materia novelesca encuentra expresión en la gran cantidad de relatos enmarcados por esquemas formulísticos -items, guiones, encabezamientos númericos o lingüísticos ...-que limitan las posibilidades de las distintas voces narrativas. Los cambios de perspectivas son frecuentes y hasta súbitos. Novela de construcción polifónica, la narración misma parece quedar aprisionada en su confusión por voces impersonales, por esquemas implacables que congelan el caótico espacio narrativo. Por otra parte, la composición narrativa parece reproducir un juego de cajas chinas o de espejos enfrentados. No sólo la numeración señala pautas, los relatos son contenidos por otros relatos disputando la fiabilidad de sus proposiciones. Todo parece quedar siempre en manos de fuerzas cada vez más ocultas. Es el caso de la batalla de Cnossos y Cataelix, contenida en la imaginación de Micael, tomada a su vez de las tarjetas computarizadas de Gustav y prefiguradas por el Duque de Rocanegras en su espectacular viaje laberíntico. Lo mismo parece suceder con la figura del prestidigitador, que asume todas las posibilidades, o con el manuscrito, que Rubén entrega al Historiador. Se anula el tiempo en la novela, pero también la confianza en lo meramente figurativo.

De esta manera, la escritura por sí misma representa un último nivel de encarcelamiento, pero supone también una potencial superación. El espacio caótico de la novela, ese fracaso del conocimiento y del destino del hombre frente a sus realidades, se resuelve en destrucción por lo abyecto, lo explosivo o lo ininteligible; a través del discurso se expresa una cierta idea de circularidad, de aniquilación a partir de la confrontación de términos y elementos contradictorios. 
Pero también se propone una solución abierta en la pervivencia de la palabra: el "escritor fascinado por la palabra palabra” cede su potencial a otros más allá de la muerte física; el prestidigitador grita su mensaje aunque éste sólo consista en un balbuceo inicial, o precisamente por eso. La palabra es cerrojo y llave al mismo tiempo; simultaneidad contenida en los inicios de la novela:

... en remolino avanza esta palabra hecha de error de diversidad de cambio, en remolino esta palabra se equivoca, se multiplica, se transforma, en remolino esta palabra engendra palabras que se combaten, en remolino somos esta palabra que muere y renace en remolinos.

Desde luego, en breve espacio resulta poco menos que imposible, no sólo agotar los aspectos significativos básicos de la novela, sino desarrollar suficientemente aquellos señalados anteriormente. Por lo demás, se trata de una obra densa, que tal vez por pretender abarcar diversos niveles de realidad a modo de compendio y por la complejidad misma de la materia novelada, supone para el lector una buena dosis de tenacidad y paciencia. Sin embargo, con respecto a esta suma lingüística que es Abrapalabra, lo menos discutible es que se trata de una de las novelas más importantes en la literatura venezolana de las últimas décadas y en la joven narrativa latinoamericana.

Abrapalabra no sólo nos remite a una visión de conjunto, integradora, referida a la vida histórica y cultural de una realidad nacional determinada. Supera las fronteras y se proyecta hacia las otras realidades latinoamericanas, que comparten no sólo elementos comunes de historia y de lengua, sino también el resultado de una cultura dependiente y enajenante, y de un poder que se encarga de sustentar y producir un específico estado de cosas. La recepción del Premio Casa de las Américas sólo en parte da cuenta de la proyección continental de la novela. La ausencia premeditada de referencias históricas o geográficas explícitas apunta en esta dirección, contribuye a ampliar sus alcances. Por otra parte, la visión de mundo propuesta en la novela se encuadra en aquellas visiones de un sector de intelectuales o creadores latinoamericanos que igualmente cuestionan las condiciones de existencia de su grupo social y, en general, el estado de dominación ejercido sobre sus concretas realidades socioculturales.

Por otra parte, pocas novelas han emprendido esta sintesis tentativa de interpretación de una totalidad histórica y de experimentación lingüística llevada a consecuencias últimas. En este sentido, Abrapalabra guarda ciertos nexos con viejas y nuevas tradiciones de la literatura hispanoamericana y venezolana contemporánea. Al hablarse de experimentación no pueden dejarse de lado ni la vanguardia poética ni los intentos de novelistas como Cortázar en Rayuela o Cabrera Infante en Tres tristes tigres. Con respecto a la ambición de su proyecto, guarda conexión, por su intento sintetizador o totalizante, con

'Abrapalabra, op. cit., 20-21. 
obras como las primeras novelas de Vargas Llosa; De donde son los cantantes, de Severo Sarduy; Terra nostra, de Fuentes, o La consagración de la primavera, de Carpentier; obras magnas de la narrativa de los últimos años, producidas por autores mayormente ubicables en torno al fenómeno de boom y con otros autores latinoamericanos como Galeano, o Roa Bastos en el caso concreto de Yo, el Supremo, con la que guarda especial afinidad en su concepción de la escritura y del poder. (Con respecto a la narrativa venezolana de las últimas décadas, asume las experiencias de corrientes como las iniciadas por Garmendia y González León o por narradores tan distintos como Oswaldo Trejo o José Balza, sin intentar aquí discriminar visiones.) Estas mínimas referencias literarias muestran hasta qué punto la narrativa latinoamericana, en su proceso de renovación iniciado en los años cuarenta, ha incorporado a su proyecto aquellos otros propuestos desde las distinas narrativas nacionales; hasta qué pu nto ha alcanzado la posibilidad de constituir un corpus generativo de un sistema literario relativamente autónomo, aquello que hace algunos años aún asomaba con cierta timidez entre los críticos: la madurez de la narrativa latinoamericana avalada por su continuidad. 
